\title{
PERCEPÇÕES DE PROFISSIONAIS SOBRE A VIOLÊNCIA CONTRA AS MULHERES NOS SERVIÇOS DE PROTEÇÃO NO MUNICÍPIO DE SÃO JOÃO DEL-REI - MG
}

\section{PROFESSIONALS' PERCEPTIONS OF VIOLENCE AGAINST WOMEN IN PROTECTION SERVICES IN THE CITY OF SÃO JOÃO DEL-REI}

\section{PERCEPCIONES DE PROFESIONALES DE VIOLENCIA CONTRA LAS MUJERES EN LOS SERVICIOS DE PROTECCIÓN EN LA CIUDAD DE SÍO JOÍO DEL-REI - MG}

\section{Resumo}

Ana Caroline Matos Soares ${ }^{1}$ Márcia Barroso Fontes ${ }^{2}$

\begin{abstract}
Este artigo apresenta as percepções dos profissionais que atuam nos serviços de atendimento às mulheres em situação de violência no município de São João del-Rei/MG. A pesquisa teve como base a Política Nacional e o Pacto Nacional pelo Enfrentamento à Violência Contra a Mulher, que propõem, em linhas gerais, a articulação entre os serviços e o fortalecimento de uma rede de apoio que visam ao enfrentamento da violência contra as mulheres. O estudo consistiu em uma pesquisa quali/quantitativa, na Delegacia Especializada no Atendimento à Mulher e no Centro de Referência Especializada em Assistência Social da Cidade de São João del-Rei. Percebeuse, pelos dados obtidos, uma situação preocupante em termos de violência na referida cidade, além de alguns entraves no seu enfrentamento, como ausência de capacitação e especialização dos profissionais, inexistência de uma rede articulada e escassez de ações municipais baseadas na Política e no Pacto Nacional.
\end{abstract}

Palavras-chave: Violência Contra as Mulheres. Delegacia Especializada no Atendimento à Mulher. Centro de Referência Especializada em Assistência Social. Rede de Atendimento.

\begin{abstract}
This article presents the perceptions of professionals who work in services for women in situations of violence in the city of São João del-Rei / MG. The theoretical basis of the research was the National Policy and the National Pact for Confronting Violence Against Women, which, in general, propose the articulation between services and the strengthening of a support network aimed at tackling violence against women. The study consisted of a qualitative and quantitative research at the Specialized Police Station for Assistance to Women and at the Specialized Reference Center for Social Assistance in the City of São Joao del-Rei. It was perceived by the data obtained a worrying situation in terms of violence in that city, in addition to some obstacles in its confrontation, such as: lack of training and specialization of professionals; lack of an articulated network; and scarcity of municipal actions based on the Policy and the National Pact.
\end{abstract}

Keywords: Violence Against Women. Specialized Police Station for Women. Reference Center Specialized in Social Assistance. Service network.

\section{Resumen}

Este artículo presenta las percepciones de los profesionales que trabajan en servicios para mujeres en situaciones de violencia en la ciudad de São João del-Rei / MG. La investigación se basó en la Política Nacional y el Pacto Nacional para Combatir la Violencia contra las Mujeres, que, en general, proponen la articulación entre los servicios y el fortalecimiento de una red de apoyo destinada a combatir la violencia contra las mujeres. El estudio consistió en una investigación cualitativa / cuantitativa, en la estación de policía especializada en asistencia a mujeres y en el centro de referencia especializado en asistencia social de la ciudad de São João del-Rei. Se notó, a partir de los datos obtenidos, una situación preocupante en términos de violencia en esa ciudad, además de algunos obstáculos en su confrontación, como la falta de capacitación y especialización de profesionales, la falta de una red articulada y la escasez de acciones municipales basadas en la Política y en el pacto nacional.

Palabras clave: Violencia contra la mujer. Comisaría especializada para mujeres. Centro de referencia social.

\footnotetext{
${ }^{1}$ Graduada em Serviço Social (UFOP). Especialista em Política de Assistência Social/SUAS. Mestra em Economia Doméstica (UFV). E-mail: anacarolineas21@hotmail.com

${ }^{2}$ Doutora em Demografia (UFMG) e professora da UFV. E-mail: anacarolineas21@hotmail.com
} 


\section{INTRODUÇÃO}

A violência contra as mulheres possui raízes históricas e, muitas vezes, está relacionada a diferentes estruturas sócio-histórico-culturais. Esses crimes têm colocado, cada vez mais, mulheres em situações de risco, incapacitando-as para o trabalho, o estudo e a vida em sociedade.

No Brasil, assim como em outros países da América Latina, a violência pode ser entendida mediante o contexto do regime colonial, escravocrata e patriarcal. Segundo Costa e Sardenberg (2008), a sociedade rural brasileira foi expressa por condições que situavam a mulher em uma situação de precariedade e sem direitos civis, sociais e políticos. O sistema patriarcal, segundo Arruzza (2015), constitui-se como elemento da formação social e econômica brasileira, reproduzido e atualizado na contemporaneidade. Apesar de não serem elementos específicos do modo de produção capitalista, são recolocados e intensificados nesse modo de produção. Os valores reproduzidos socialmente mantêm-se ainda conservadores, o que fundamenta a relação desigual entre os gêneros, incidindo na opressão dos homens sobre as mulheres. A título de ilustração, no Brasil, segundo dados divulgados pelo Sistema de Indicadores de Percepção Social (SIPS, 2014), 58\% de 3.810 entrevistados em maio e junho de 2013 concordaram com a afirmação "se as mulheres soubessem se comportar haveria menos estupros". Na mesma pesquisa, 82\% concordaram com a frase "em briga de marido e mulher não se mete a colher".

De acordo com Ribeiro e Rosa (2010), a temática de violência contra as mulheres se destaca na década de 1980, juntamente com a questão da saúde da mulher. O tema foi sendo incorporado gradativamente nas agendas políticas e institucionais, com manifestações diversas em todo o país, o que contribuiu para a criminalização e punição dos agressores. Segundo Bandeira (2009), a violência contra as mulheres é um dos principais fenômenos que as feministas buscam erradicar. Para tanto, procuram participação de diversos setores, em especial na legislação e nos recursos jurídicos.

O contexto político, social e econômico do Brasil propicia a criação de mecanismos de estratégias distintas de outros países para o enfrentamento à violência contra as mulheres. Nesse aspecto, os serviços de atendimentos representam uma peça importante na viabilização de direitos e diminuição dessa violência. Ações baseadas no Pacto Nacional pelo Enfrentamento à Violência Contra a Mulher (PNEVM) e na Política Nacional de Enfrentamento 
à Violência Contra as Mulheres (PNEM) foram instituídas, de modo a contribuir para a saída das mulheres do contexto violento.

O processo de formulação e implementação dessas políticas públicas foi construído a partir de diálogos, tensões e disputas entre os movimentos feministas com o Estado (MATOS, 2014). A conquista da legitimidade da violência denunciada pelas mulheres foi um avanço que fomentou a criação de políticas públicas de enfrentamento. A institucionalização de secretarias, leis e ações específicas fundamentaram políticas públicas nacionais e regionais como respostas às violências vividas pelas mulheres.

Em 2003, criou-se a Secretaria Especial de Políticas para as Mulheres (SPM), que deu base às solicitações do movimento, incluindo as lutas históricas no país, na busca por direitos específicos na questão da violência contra as mulheres e nas estratégias para o seu enfrentamento. Uma exclusividade da secretaria foi considerar medidas que visavam à prevenção da violência e à emancipação das mulheres e não apenas a visão criminal da violência. Assim, a gestão contou com a participação de diversas áreas profissionais como, por exemplo, Antropologia, Ciências Sociais, Ciências Humanas e Ciências Políticas (ARAÚJO, 2011). Faz-se relevante pontuar que as políticas públicas criadas a partir da SPM são elaboradas a partir da interlocução de todas as esferas governamentais, em níveis municipais, estaduais e federal e de acordos entre os órgãos.

Em relação ao enfrentamento à violência contra as mulheres, a SPM modificou o tratamento à questão, ao apresentar processos de fortalecimento das ações, monitoramento das políticas públicas e estratégias de gestão (MARTINS; CERQUEIRA; MATOS, 2015). Assim, a SPM fomentou que as políticas públicas de enfrentamento fossem estabelecidas por meio de criação de normas e padrões de atendimentos, incentivo à construção das redes de serviços, prevenção à violência, aperfeiçoamento da legislação, acesso das mulheres aos serviços especializados, entre outros (BRASIL, 2011).

Um dos principais avanços da SPM se refere à criação do PNEVM. Lançado em 2007, concebido pelo Governo Federal a partir de mecanismos advindos da Lei 11.340/06 (Lei Maria da Penha) $)^{3}$. O Pacto Nacional possui em sua estrutura cinco ações, dentre elas a ampliação e fortalecimento da rede de serviços para as mulheres em situação de violência, focados no presente artigo (BRASIL, 2011, P. 45).

\footnotetext{
${ }^{3}$ A Lei no 11.340/2006, conhecida como Lei Maria da Penha, representou o maior marco legislatório na conquista de direitos. A partir desta lei, foram elaboradas políticas públicas de enfrentamento à violência contra as mulheres no Brasil, que direcionam ações específicas para o público a nível nacional. A Lei Maria da Penha é de caráter institucional, contribuindo para a criação de políticas públicas no Brasil, uma vez que descreve formas físicas, psicológicas, sexuais, patrimoniais e morais de violência e fundamenta critérios criminais para responsabilizar os agressores (BRASIL, 2006).
} 
Além do PNEVM, a PNEM, criada em 2011, objetiva fundamentar princípios, diretrizes e ações voltadas para a temática de violência. Existem quatro eixos estruturantes da política nacional, quais sejam: prevenção, assistência, garantia de direitos e combate à violência. Nesse aspecto, o presente artigo destaca o eixo que trata a assistência e segurança pública, a fim de observar de que forma ocorre a incorporação da Política Nacional nas ações das instituições, verificar a implementação dos serviços e seus limites.

Sabe-se, porém, que a criação de serviços especializados pontuais não garante a erradicação da violência. São essenciais a articulação da rede, a capacitação dos profissionais, e, principalmente, mudanças sociais e culturais inseridas na perspectiva de gênero.

Em São João del-Rei, existem duas instituições às quais as mulheres podem recorrer em caso de situação de violência: a Delegacia Especializada no Atendimento da Mulher (DEAM) e o Centro de Referência Especializada em Assistência Social (CREAS). A DEAM é uma instituição especializada no atendimento às mulheres em situação de violência, contudo divide espaço físico com outras delegacias que possuem outros propósitos. O CREAS presta diversos serviços à população e, entre eles, realiza o atendimento às mulheres em situação de violência. Tanto a DEAM quanto o CREAS fazem parte da rede abarcada pela PNEVM e PNEM. Contudo, fez-se necessário um estudo que analisasse a aplicação dessas normas, de acordo com a visão dos próprios profissionais que atuam nessas instituições.

Diante disso, o objetivo desta pesquisa foi analisar e descrever as práticas presentes nos serviços de atendimento às mulheres em situação de violência no município de São João del-Rei/MG. A pesquisa foi embasada na perspectiva da PNEM e do PNEVM, que propõem, dentre seus parâmetros, a articulação entre os serviços e o fortalecimento de uma rede de apoio que visem ao enfrentamento da violência contra as mulheres. $O$ estudo analisou o conhecimento e a prática dos profissionais em relação ao PNEVM e à PNEM, além de averiguar a participação deles em eventos, capacitações e outras atividades que subsidiem condutas profissionais.

O tema abordado neste estudo científico é, pois, relevante por compreender a urgência de mais pesquisas acerca do fenômeno da violência contra as mulheres, especialmente, análises sobre os serviços de atendimento que considerem a percepção dos trabalhadores ali inseridos. Espera-se que estudos dessa natureza contribuam para a formulação e a execução de políticas públicas e sociais, tendo em vista as diferentes necessidades e a garantia dos direitos das mulheres atendidas em situação de violência. 
A inovação da presente pesquisa se dá pelo pouco número de estudos quali/quantitativos em municípios como o de São João del-Rei em relação às instituições que prestam atendimento às mulheres: DEAM e CREAS.

\section{PERCURSO METODOLÓGICO}

Para a realização deste estudo, foi escolhida a cidade de São João del-Rei/MG, por considerar que as características sócio-histórico-culturais da cidade são fortemente influenciadas por instituições tradicionais e conservadoras, como os centros militares e instituições religiosas cristãs, o que potencializa o sistema patriarcal, com reprodução de valores e normas, assim como sujeitos e saberes, os quais inferiorizam e buscam controlar as mulheres em diversos ambientes. Conforme Lima (2010), mais de sessenta casos de agressão contra a mulher chegam à Delegacia Civil do município, todos os meses. Dentre os municípios da sua microrregião, São João del-Rei é o único que possui uma delegacia especializada no atendimento a mulheres em situação de violência. Há também o CREAS que, apesar de não ser especializado no atendimento às mulheres, realiza esse tipo de serviço.

A população estudada abarcou todos os profissionais que lidam e atendem diretamente as mulheres usuárias e que concordaram em participar da pesquisa. No total, participaram 14 profissionais que atuam na DEAM, sendo 64,3\% homens e 35,7\% mulheres, e seis que atuam no CREAS, sendo $16,7 \%$ homens $83,3 \%$ mulheres. Baseou-se no método quali/quantitativo, utilizando-se de questionário semiaberto aplicado aos profissionais dos referidos setores. Além de responderem a um questionário, os 14 participantes foram entrevistados e são identificados nesse artigo de E1 a E14, com intuito de manter o sigilo.

Para análise dos resultados, inspirou-se na análise temática, com ênfase na análise de conteúdo de Bardin (2016), que sugere: pré-análise - leitura flutuante das transcrições, exploração do material - categorização e agrupamento dos dados, e tratamento dos resultados e interpretação - interpretação dos resultados, inferências e discussão. Os dados quantitativos foram tabulados privilegiando as médias e as correlações das respostas obtidas.

O trabalho foi submetido e aprovado pelo Comitê de Ética em Pesquisa com Seres Humanos (CEP) da Universidade Federal de Viçosa (UFV). 


\section{A INCORPORAÇÃO DAS POLÍTICAS NO DEAM}

O objetivo da DEAM, segundo Pasinato e Santos (2008), fundamenta-se na investigação de crimes contra o gênero feminino, presumidos no Código Penal. As ações realizadas na DEAM possuem caráter de responsabilização e criminalização, praticadas pelo viés de apuração, investigação, abertura de inquéritos (SILVA, 2017). A DEAM constitui o eixo de segurança pública, com a finalidade de punibilidade aos responsáveis pelas violências (BRASIL, 2011).

A incorporação do PNEVM e da PNEM nas ações da DEAM se dá de forma contraditória, pois $64 \%$ dos profissionais afirmaram conhecê-los, enquanto 35,7\% não possuem conhecimento algum sobre eles. Esse dado é alarmante e expõe a necessidade de um maior incentivo à adoção do PNEVM e da PNEM pelos profissionais, para que todos conheçam profundamente as políticas, os objetivos e princípios, que servem como pilares para um atendimento adequado. Nesse aspecto, outro dado revela a precariedade da capacitação das equipes, uma vez que 57,1\% responderam não terem participado de eventos/estudos sobre o PNEVM. Os outros 42,9\% participaram de eventos municipais, como o Seminário de 10 anos da Lei 11.340/06 (Lei Maria da Penha). Portanto, percebe-se a necessidade urgente de maior participação e capacitação dos profissionais, não apenas em âmbito municipal, mas estadual e federal, para maximizar as possibilidades de contatos, articulação de estudos e troca de conhecimento. Ao responderem se o serviço de atendimento às mulheres segue a PNEM e suas diretrizes de atuação, 78,6\% colocaram não seguir. Essa informação sugere uma desarticulação dos próprios profissionais, além da falta de sistematização dos dados e desconhecimento das ações ofertadas na delegacia. Os outros 21,4\% afirmaram segui-la na prestação dos serviços, no processo de denúncia e representação e na instauração de medida protetiva.

Ao serem indagados sobre a existência de um local que garanta a privacidade e sigilo profissional, 71\% afirmaram existir a presença desse espaço na DEAM. Tais espaços são obrigatórios para garantir o sigilo no atendimento às mulheres, em decorrência da situação sensível e grave da chegada delas a esses locais. Alguns avanços foram também destacados pelos profissionais, uma vez que $78,6 \%$ afirmaram que houve melhoria do serviço nos últimos anos, em relação ao espaço físico e à aquisição de novos materiais.

De acordo com Silveira (2006), a falta de dados sistematizados produz um desgastante desempenho dos profissionais no enfrentamento à violência contra as mulheres. $\mathrm{A}$ 
inconsistência do perfil das mulheres, das ações, dos avanços e dos limites dos serviços indica uma dúvida sobre sua real efetividade na vida dessas mulheres. Desse modo, os serviços prestados nas instituições denotam a falta de incorporação nas políticas de atenção direcionadas à violência.

Quanto às ações realizadas na DEAM, percebeu-se serem condizentes com o objetivo da instituição, ou seja, possuem um caráter de responsabilização, via segurança pública. Nesse sentido, a instituição não dispõe de atendimento psicossocial, sendo uma das principais necessidades de acordo com os profissionais. Contudo, os funcionários apontaram algumas deficiências, como a inexistência de Assistente Sociais e Psicólogos, a falta de atendimento exclusivo de uma equipe para a DEAM, o direcionamento para um local em que a vítima não fique próxima ou dependente financeiramente do agressor e, com isso, o carecimento de Casa Abrigo. Por meio dessa informação, infere-se a urgência de atendimento e acompanhamento psicossocial dentro da DEAM. A atuação de uma equipe multidisciplinar nos serviços de responsabilização, contribui para minimizar a desistência da denúncia, além do acolhimento psicológico e do acesso às informações relacionadas aos direitos da mulher. Além disso, a falta de articulação entre os serviços também foi apontada:

A rede não é uma teia, falta articulação entre os serviços. Além disso, vejo a falta de atendimento psicossocial, mais humanitário e espaço mais apropriado. (E13).

Outra dificuldade observada é a ausência de levantamento de perfil das mulheres atendidas. A inexistência de dados quantitativos representa também uma contrariedade institucional, uma vez que dificulta o processo de avaliação e ações que podem ser operacionalizas a partir das características das mulheres atendidas. Além da necessidade de diferentes atuações no atendimento às mulheres, outro fator relevante é a existência de locais adequados para recebê-las, uma vez que parte das mulheres se sentem constrangidas e desconfortáveis em ambientes pouco acolhedores.

Houve uma melhoria na infra-estrutura e de pessoal, de espaço físico e pessoal, além de recursos físicos. O novo prédio oferece mais conforto. (E5).

Foi citada também a formação de equipe especializada e o apoio no trabalho. Em consequência das melhorias, as mulheres passaram a ser mais informadas sobre o contexto de violência, a partir de um ambiente institucional que possibilite a denúncia.

Houve uma melhoria na infraestrutura da delegacia. Há também uma maior conscientização das mulheres sobre seus direitos, que passaram a entender que a agressão não se limita no aspecto físico, mas também moral e psicológico. (E2). 
Percebe-se, pelos resultados obtidos, avanços nos aspectos físicos da delegacia e a ampliação do acesso as informações relacionadas aos direitos das mulheres. Todavia, não foram observadas melhorias na eficácia dos serviços prestados às mulheres, em relação à independência, saída do contexto violento, finalização do processo, entre outros, pois, apesar dos avanços, foram observadas algumas limitações que dificultam a prestação dos serviços e no atendimento, de forma integral. Dentre as percepções, estão a falta de cooperação das partes para o andamento do processo, a ausência de recursos humanos, físicos e financeiros, a falta de interdisciplinaridade entre os profissionais, a pouca integração entre as áreas criminal, social e psicológica, o número insuficiente de cursos de capacitação - como seminários -, a ausência de informações acerca dos casos e do acompanhamento adequado as mulheres, entre outras ações.

Segundo Bandeira (2009), os ideais conservadores presentes no atendimento contribuem também para reforçar o comportamento ideal feminino atribuído às mulheres. $A$ ideia de que a violência doméstica é matéria da vida particular é reproduzida pelos agentes públicos masculinos dentro das instituições. Contudo, de acordo com Scott (2016), o conhecimento histórico e as realidades vividas entre homens e mulheres fazem parte do processo pelo qual o gênero é produzido. Assim, existe um aspecto relacional que configura a construção dos gêneros, que podem ser expressos de modos distintos, com reconfigurações dos sujeitos, das relações, dos saberes e da sociedade.

Nesse aspecto, os profissionais podem igualmente possuir as ideias dicotômicas e reproduzi-las nos atendimentos às mulheres em situação de violência, fortalecendo e naturalizando as opressões e a desigualdade de gênero. As limitações observadas indicam que, apesar das melhorias de recursos físicos e humanos, existe um longo caminho a ser percorrido para um atendimento eficaz.

Falta recursos materiais. Ex: viaturas. Falta atendimento mais humanizado também. Além disso, falta mais facilidade de acesso aos demais departamentos. Ex: Corpo de delito, necessita ser no mesmo prédio para facilitar o atendimento completo às vítimas. Necessita de profissionais mais qualificados e funcionários para um melhor atendimento. (E10).

A contingência de recursos humanos, poucas especializações, a falta de interesse dos governos para a articulação das redes intersetoriais provoca falhas na execução do serviço, como afirma Pasinato (2015). A baixa capacitação e qualificação dos profissionais que lidam com as mulheres resulta na intimidação, incompreensão e senso comum sobre o fenômeno da violência. Desse modo, as dificuldades da instituição e do serviço reverberam na inviabilização dos direitos das mulheres. Portanto, fazem-se necessárias mais políticas que abarquem a 
proteção efetiva das mulheres e subsidiem condições para a sua retirada do contexto de violência.

Além disso, a inexistência ou a falta de articulação da rede de enfrentamento se configura como uma problemática. De acordo com Resende e Andrade (2014), a articulação entre os serviços é de suma importância para atender aos diversos aspectos das mulheres, em razão da vulnerabilidade à qual estão expostas. A interlocução entre os serviços de saúde, assistência e segurança pública constitui uma maior possibilidade de retirada das mulheres do cenário violento, como expõem os profissionais:

Faltam profissionais como psicóloga, assistente social... A rede não está completa. Muitas vítimas têm outras questões a serem trabalhadas e não temos o preparo para atender a todas as demandas delas. (E1).

Há uma reincidência dos casos. Em muitos casos, a vítima volta para o convívio com o agressor, tendo em vista a dependência financeira, psicológica. (E4).

A demanda psicossocial presente nas instituições de responsabilização, como a DAEM, transtorna o real objetivo das delegacias da mulher. Segundo Silveira (2006), as delegacias extraviam as características policiais para atenderem às demandas psicossociais das mulheres usuárias. A inexistência de instrumentos de trabalho dificulta uma intervenção propícia, de caráter policial, nos casos mais graves, restringindo essa atuação. Além disso, as delegacias especializadas possuem dificuldades internas entre os próprios funcionários. Conforme Silveira (2006), as delegacias de mulheres refletem um complexo campo de noções que inabilitam e rebaixam os profissionais e as mulheres atendidas. No esquema de corporação policial, 0 trabalho dentro de uma delegacia especializada é visto como degradante e de menor importância, sendo um local de menor valor na estrutura social e policial. Os limites institucionais invalidam a finalidade do serviço, uma vez que dispensam os diferentes interesses das mulheres, que procuram não só a punição dos agressores, mas também a interrupção da violência, a segurança e a justiça. Assim, a participação da delegada e da escrivã no processo de estrutura da rede fica comprometida, resultando no acúmulo de competências e demandas que poderiam ser de outros serviços.

Outra problemática se refere à ausência de diálogo entre as instituições, que restringe o enfrentamento à violência ao âmbito de atendimento e dificulta ações e estratégias conjuntas para confrontar a questão. Segundo Pasinato (2015), as redes de serviços fortalecem a associação de instituições para atingir uma determinada finalidade. No caso da rede de atendimento, é imprescritível a discussão entre as entidades, por conta do caráter intersetorial e interdisciplinar que forma a rede. As ações realizadas pelos entes necessitam ultrapassar a 
superficialidade de atendimentos e encaminhamentos, para avançar na viabilização de direitos às mulheres. Com isso, a ideia de rede, para Resende e Andrade (2014), necessita de elaboração prévia, com vistas a atender, de forma adequada - articulada aos diversos setores e de caráter transversal -, o enfrentamento da violência contra as mulheres. Nesse sentido, a rede de enfrentamento é essencial, uma vez que é necessária a atuação de vários serviços de assistência, como casa abrigo, geração de renda, entre outros. A falta de uma rede articulada se reflete na precariedade dos serviços/atendimentos, na interrupção do desenvolvimento continuado e qualificado dos/as profissionais e na continuidade das mulheres no ambiente violento, como aponta um profissional:

Para aquelas vítimas que tomam coragem de se libertar do agressor fisicamente, muitas vezes elas acabam não conseguindo se libertar financeiramente do mesmo, pois algumas delas não tem condições de prover seu sustento. É preciso que estas vítimas sejam direcionadas ao mercado de trabalho e a locais como abrigos ou casas especializadas, onde possam se manter longe do seu algoz. É necessário também que se direcione os trabalhos e o aspecto investigativo para áreas rurais, pois são nestes locais onde se encontram vítimas mais desamparadas, quer seja pela falta de conhecimento dos seus direitos, quer seja pela tradição do matrimônio que não pode ser desfeito, mesmo diante da violência diária. (E12).

Em consonância com a questão, Campos e Brasil (2017) expõem que a invisibilidade do fenômeno da violência ocorre em decorrência das opressões de gênero expost nas relações sociais. Os traços territoriais do meio rural fundamentam a precariedade ao acesso das mulheres às instituições. Assim, elas encontram inúmeras dificuldades de realizar a denúncia, a depender do contexto em que estão inseridas. Os obstáculos enfrentados pelas mulheres do campo podem ocorrer pela distância entre sua residência e as instituições de atendimento, privação de informações sobre o conceito e formas de violência, além da dificuldade de acesso aos direitos básicos,

Enfim, por meios de avanços e limitações, observou-se também alguns desafios para a prestação dos serviços, de forma a atender todas as demandas. Desse modo, alguns dos desafios apresentados pelos profissionais tangem à dilação dos processos no judiciário, à ineficácia da medida protetiva, entre outros, como exprimem os profissionais.

Os desafios estão em lidar com os fatos sofridos pelas vítimas, não conseguindo dar celeridade merecida aos processos. (E3).

O maior desafio é obter maior celeridade no atendimento e nos desdobramentos da investigação. (E9).

Só a medida protetiva não garante a proteção da vítima. [...], é necessário garantir a proteção para a mulher de forma efetiva. (E7). 
Infere-se, a partir dos escritos acima, que o processo jurídico, por vezes, delonga e fomenta o abandono do caso pelas mulheres. O prolongado período de resolução dos processos debilita os profissionais, o que contribui para a exaustão, diante dos casos não solucionados. A Lei 11.340 dispõe que a renúncia da "queixa" é aceita mediante a sua representação perante o juiz, em audiência própria para esse objetivo. Os casos condicionados a representação poderão ser retratados. Além disso, é necessário suprir a coerência de profissionais especializados, para que os eles possam averiguar e acompanhar detidamente os processos.

Sendo a única escrivã nessa delegacia especializada, fica difícil dar andamento aos expedientes, atender as vítimas, tirar plantões, prontidões, etc. O volume excessivo acaba prejudicando a conclusão dos procedimentos. (E1).

A sobrecarga de funções para poucos profissionais contribui para gerar falhas nas intervenções. Segundo Silveira (2006), os serviços fragmentados e isolados repercutem na saúde dos profissionais que lidam diretamente com as mulheres, em consequência dos limites de resolução dos casos. O planejamento para a construção de estratégias e a avaliação das ações também se restringem, uma vez que falta capacitação específica para os funcionários em relação a métodos de planejamento e avaliação. Além disso, a escassez de ações integralizadas limita segurança das mulheres e reduz a possibilidade de autonomia das mesmas.

Como desafios, destacaram-se a posição da mulher em situação de violência e necessidade de conscientização delas sobre o fenômeno da violência.

Fazer com que boa parte das vítimas entenda que a partir da primeira agressão, quer seja ela física, psicológica ou moral, o agressor não vai mudar seu comportamento com uma simples representação da vítima junto ao órgão policial. É preciso que ela tenha coragem de dar um basta aquela situação. (E13).

\section{[...] É necessário a persistência da vítima na continuidade do atendimento. (E6).}

É interessante pontuar, de acordo com Gregori (1993), a dinâmica existente entre a relação oprimida e opressor. As mulheres se situam na posição de vítima, fortalecendo o estereótipo da passividade feminina. Contudo, as relações de violência são perpassadas por momentos de poder, que se instaura pelo agressor e também pela agredida. Nesse contexto, nas instituições de atendimento predomina o ideário de vítima, que coloca a mulher em uma passividade inexistente. A desistência da denúncia pode ser interpretada de distintas formas pelos profissionais, principalmente pela noção de criminalização, sem a veracidade que culminou no abandono do processo. A concepção de certo e errado, a determinação dos 
passos que as mulheres precisam seguir para se afastarem dos parceiros contribuem para a divergência dos fatos. A interpretação dos profissionais difere da das mulheres, gerando um atrito e uma revitimização que ocasiona a desistência. As mulheres são vitimadas sob diferentes violências, com recorte de raça e classe.

Faz-se interessante frisar que as propostas de enfrentamento aceitas pelo Estado conduzem a abordagens pelo viés da criminalização, que é aprovada no processo de institucionalização das políticas públicas. Os campos feministas propõem, para 0 enfrentamento à violência, não apenas a abordagem criminalizante, mas uma perspectiva ampla, pelo viés de gênero, para enfrentar a raiz da violência. Além disso, de acordo com Santos (2010), inseridos em um contexto de neoliberalismo, os serviços e leis para as mulheres não atuam de forma articulada, como propõe a Lei 11.340/06 (Lei Maria da Penha), uma vez que não há uma sincronia em suas ações. Salienta-se, segundo Campos e Brasil (2017), a indispensabilidade de ações de sensibilização relacionadas às questões de gênero e de violência contra as mulheres. A capacitação profissional necessita estar atrelada no trabalho em rede em nível municipal. Assim, a partir dos dados, percebe-se a necessidade urgente de mudanças para o enfrentamento à violência contra as mulheres.

\section{A INCORPORAÇÃO DAS POLÍTICAS NO CREAS}

O CREAS realiza ações voltadas para a assistência social, com intervenções preventivas, medidas socioeducativas, entre outros. Os atendimentos prestados às mulheres em situação de violência no CREAS se baseiam nas legislações vigentes, como a Lei 11.340/06 (Lei Maria da Penha), ações advindas do Ministério do Desenvolvimento Social (MDS), Secretaria Nacional de Assistência Social (SNAS), Orientações técnicas para os CREAS, entre outros (BRASIL, 2011).

Em relação à absorção da PNEM e do PNEVM no CREAS, observou-se a pouca e/ou nenhuma apreensão da mesma no exercício profissional. A política prevê ações de prevenção e combate à violência. Desse modo, determina que os serviços destinados às mulheres em todo o Brasil sejam pautados em normas e legislações nacionais e internacionais. No CREAS, apesar de $80 \%$ dos profissionais afirmarem conhecer a PNEVM e o PNEM, eles afirmaram não os seguir na prática.

A partir desse dado, infere-se uma problemática e desafios da instituição. $O$ desconhecimento e a consequente não aplicação do PNEVM e da PNEM nos serviços ali prestados retratam uma precariedade no percurso dos atendimentos que refletem diretamente 
nas mulheres atendidas. Mais que isso, é premissa do PNEVM e do PNEM a necessidade da atuação dos serviços articulados em rede, de forma integral, multissetorial e norteado pelo princípio da transversalidade (BRASIL, 2011). Diante da inobservância do conteúdo dessas políticas, supõe-se que o CREAS não se atrela aos objetivos dessas normas, por não seguir as ações nelas estabelecidas.

Ao questionar sobre a participação em eventos/estudos sobre a PNEM, 50\% confirmaram comparecer ao seminário municipal sobre os dez anos da Lei 11.340/06 (Lei Maria da Penha). Esse dado revela que, apesar da participação de alguns profissionais nos eventos, esses representam apenas metade da equipe que possui capacitações específicas sobre a temática. Os outros $50 \%$ dos funcionários não participaram de eventos especializados. Além da participação em eventos locais, a presença em eventos regionais, estaduais, nacionais e internacionais é importante para a troca de conhecimento, fortalecimento e articulação de ideais e redes sobre as políticas específicas para as mulheres, em âmbito mundial.

Por meio da explanação dos dados, verifica-se a necessidade de mais capacitações e formações, para que o atendimento seja realizado de forma adequada, com imparcialidade e livre de valores e princípios tradicionais. Contudo, para além das especializações, o interesse pela temática deve ser amparado em níveis municipais, estaduais e federais. Assim, é importante uma rede de apoio para a captação de recursos financeiros e humanos.

No que se refere às ações, ao questionar sobre a procura dos serviços, $60 \%$ afirmam média quantidade de procura das mulheres para o serviço ofertado. 10\% afirmam pouca procura e 30\%, muita. Esse cenário indica uma contradição de percepção entre os profissionais, com a dispersão de informações relacionadas ao número de mulheres atendidas. Nesse aspecto, deduz-se o pouco conhecimento sobre os atendimentos. Quando questionados se o serviço é suficiente para atender à demanda, $80 \%$ informaram ser o bastante para a procura. Até o mês de maio de 2019, cerca de 110 mulheres são acompanhadas no serviço. Percebe-se que a reduzida equipe e o período de trabalho realizado contribuem para um atendimento fragmentado e com pouca possibilidade de intervenções que visem abarcar as diversas nuances da violência contra as mulheres.

O dado posterior se refere aos serviços de atendimento à mulher existentes na presente instituição, em que 100\% responderam ter foco na violência doméstica e familiar, ou seja, mulheres em vulnerabilidade social e situação de violência a partir do contexto doméstico e/ou com envolvimento de pessoas com laços afetivos.

Além disso, com relação à chegada de novos recursos (humanos, físicos e financeiros), até o final do ano de 2022, $100 \%$ dos profissionais afirmaram não existir previsão de 
recebimento. Para um atendimento e acompanhamento das mulheres de forma aprofundada, faz-se importante a disposição de recursos, pois eles propiciam a organização e a autonomia da equipe para traçar estratégias de atuação efetivas. Reputa-se, desse modo, que a falta de verba na atenção à violência contra as mulheres significa a falta de interesse dos entes responsáveis, em nível municipal, estadual e federal, para o enfrentamento da problemática.

Em consonância com as ações desenvolvidas na instituição, ao questionar algum serviço que não faz parte da rede atual e que os profissionais pensam que deveria fazer, apenas $20 \%$ assumiram a necessidade de mais serviços com foco na orientação processual e maior acompanhamento às mulheres. De acordo com Silveira (2006), os centros de referência possuem parte estratégica na rede de enfrentamento à violência contra as mulheres. Entretanto, constantemente, esses centros reduzem sua atuação à orientação e acolhimento, justamente pela falta de políticas públicas que se articulem com os serviços. Além disso, como se trata de um serviço público, há uma tendência maior de que os serviços sejam procurados por mulheres de baixa renda, pobres e com outras vulnerabilidades sociais. A interseccionalidade, ou seja, a relação entre diferentes eixos, como, por exemplo, gênero, raça, classe e geração, fazem-se importantes para o enfrentamento à violência contra as mulheres no CREAS.

Nesse sentido, $100 \%$ dos profissionais afirmaram realizar algum tipo de trabalho socioeducativo com o agressor e com a comunidade, por meio de eventos de prevenção à violência, como palestras no CREAS. Com o agressor, são executadas ações de atendimento/aconselhamento, orientação, conversas e acompanhamento, caso se constate vulnerabilidade.

Em relação ao espaço de sigilo profissional, 100\% afirmaram possuir local para atendimento das mulheres que garanta a privacidade das usuárias. Todos os profissionais apontam possuir levantamento (dados) do perfil das mulheres atendidas. Os dados levantados sobre as mulheres atendidas podem contribuir para traçar estratégias efetivas de projetos e ações, o que gera mais facilidade em torno da questão. É necessário, então, que haja o alinhamento das ações com o perfil das mulheres, para alcançar os objetivos da instituição. De modo a conquistar um melhor atendimento, é preciso um conjunto de esforços que gere situações favoráveis, além de recursos financeiros, para a efetivação do atendimento.

Ao serem indagados sobre o trabalho interdisciplinar, 100\% declararam possuir a interdisciplinaridade como eixo de atuação, ao articular os serviços pela rede de atendimento. A rede de atendimento, de acordo com Pasinato (2015), abarca, assim, os serviços que executam as ações, por meio do atendimento qualificado, multidisciplinar e intersetorial, com a 
integração direta entre os profissionais. Esse dado, contudo, revela discordância, uma vez que não foi observada a articulação, de forma aprimorada, entre os serviços e sim de encaminhamentos pontuais. Nesse sentido, conforme Pasinato (2006), as redes de serviços necessitam construir ações voltadas para a identificação do problema, prevenção, orientação e erradicação, em sua totalidade. A multiplicidade das questões que envolvem a violência contra as mulheres deve ser enfrentada de forma conjunta e estrutural, para integrar os serviços de atendimento às mulheres (SOUZA; CORDEIRO, 2014).

A rede de enfrentamento à violência contra as mulheres consiste na articulação, de forma organizada, entre as instituições e os serviços. O propósito da rede é desenvolver estratégias de prevenção de políticas que visem à autonomia de todas as formas das mulheres, a assistência completa a elas e a responsabilização dos agressores. Para o funcionamento da rede, é necessária a contribuição dos agentes, o diálogo entre os serviços e a construção de estratégias conjuntas para o enfrentamento à violência (BRASIL, 2011). Para além da rede, é necessário que os encaminhamentos e parcerias sejam realizados de forma completa, por meio do reconhecimento do fenômeno da violência, que incide não apenas na mulher agredida, mas em toda a sociedade. Como os serviços não são articulados, ocorre, segundo Silveira (2006), o esgotamento emocional, mental e físico dos profissionais e também das mulheres, consequências da baixa resolutividade da questão. A redução da possibilidade de solução dos casos, que garantiria os direitos das mulheres, é decorrente da fragilidade de articulação e de organização dos serviços, em especial no âmbito jurídico, que atua de maneira limitada e pontual.

No entanto, as percepções dos profissionais não incluem a articulação de rede como um dos desafios enfrentados, uma vez que, ao responderem, apontaram como desafios:

[...] a conscientização das mulheres vítimas da agressão a não desistir do procedimento do processo judicial. (E8).

[...] Dificuldade das mulheres vítimas de violência em aceitar (entender) a violência a qual é submetida...o trabalho com as mulheres para a denúncia do agressor e representação, além do tempo para liberação da medida protetiva. (E10).

A perpetuação de visões tradicionais pelos profissionais revela práticas baseadas em estereótipo de gênero, no qual as mulheres são posicionadas como vítimas e não sujeitos. Assim, para Pasinato (2015), os padrões de enfrentamento à violência contra as mulheres atingem os profissionais e também a instituição. É importante a reflexão dos agentes envolvidos sobre as dificuldades de modificar práticas e rotinas institucionais, as posturas 
pessoais baseadas em crenças e valores que não identificam as diferentes gravidades da violência contra as mulheres.

Percebe-se que um dos maiores desafios é relacionado ao processo judicial, que se prolonga por meses e até anos. A liberação da medida protetiva também aparece como um entrave, com um longo período de tempo até sua concessão. O processo lento fomenta a desistência das mulheres em denunciarem e a desesperança de conseguirem a resolução do problema pelo meio legal. Nesse sentido, as principais limitações para a execução dos serviços foram apontadas em relação ao poder judiciário e à responsabilização das próprias mulheres. Segundo os profissionais, os entraves tangem

[...] as limitações quanto ao deslocamento e saída das mulheres do ambiente violento. (E11).

[...] em alguns casos, demora da tutela, o judiciário em deferir medida protetiva e recursos da rede. (E14).

As mulheres vêm enfrentando diversas dificuldades de acesso aos serviços de atendimento, principalmente, a falta de conhecimento sobre quais são esses serviços e as formas de funcionamento. $O$ apoio advindo das instituições que prestam atendimento às mulheres em situação de violência necessita priorizar a popularização de materiais e informações, criando estratégias para a divulgação dos serviços existentes. O acesso a informações contendo as etapas do processo e o tempo médio para sua conclusão pode contribuir para a continuidade da denúncia pelas mulheres. Na DEAM, infere-se a necessidade de esclarecer, detidamente, todo o percurso do processo, além dos eventuais imprevistos (SOUZA, 2014).

No espaço jurídico, as mulheres em situação de violência são mais expostas nos processos de investigações ou penais quando precisam enfrentar o agressor em um espaço confinado. É necessário que as mulheres tenham acesso aos serviços adequados de apoio, para que seus direitos e interesses sejam manifestados e considerados pelos agentes envolvidos. De acordo com Bandeira (2009), o sistema jurídico, ao analisar os casos de violência contra as mulheres, retrata dinâmicas enviesadas pela lógica sexuada. Ao interpretar e decodificar as situações de violência vivenciadas pelas mulheres, fortifica a concepção construída como família tradicional, pois, conforme Corrêa (1982), o ideário dominante fundamenta apenas uma visão teórica de família e desconsidera outras formas de organizações familiares, contribuindo para a sua marginalização. Assim, o sistema judiciário acaba por reproduzir a divisão sexual do trabalho, poder e estereótipos de gênero. 
Pelos dados obtidos, percebe-se a inexistência da articulação dos serviços, o que configura um entrave da viabilização dos direitos das mulheres usuárias. As ações de cunho imediato e pontual, sem referência nas legislações, como a PNVEM e PNEM, representam um desafio para o funcionamento dos serviços, bem como para sua ineficácia.

\section{CONSIDERAÇÕES FINAIS}

O fenômeno da violência é, no Brasil, alvo de debates calorosos nos espaços governamentais e também não governamentais. A busca por direitos levou os movimentos feministas a serem peças fundamentais na formulação, execução e fiscalização de políticas públicas direcionadas às mulheres. Contudo, alguns desafios para rede de enfrentamento à violência e os serviços de atendimento persistem. No decorrer desta pesquisa, foram verificados alguns entraves, que dificultam a viabilização dos direitos das mulheres em situação de violência, nos serviços prestados pela DEAM e CREAS de São João del-Rei.

A escassez de capacitações dos profissionais de acordo com perspectiva de gênero demonstra a necessidade de mudança, de modo a romper com a revitimização das mulheres nesses espaços e o atendimento pautado em valores, normas e condutas que foram internalizadas socialmente e que são reproduzidas em todo o processo de atendimento.

A inexistência da rede articulada de serviços também contribui para um atendimento mais fragmentado e pontual. A organização da rede constitui uma estratégia fundamental para o trato da violência, pela diversidade de eixos para enfrentar a problemática. Além disso, outras questões foram observadas, como a incompreensão dos profissionais acerca do PNEM e de como executá-lo, a dificuldade de articular parcerias, a falta de recursos financeiros e a alta rotatividade dos profissionais contratados.

Nesse sentido, vale salientar a importância de cada instância definir claramente as suas competências e atribuições, visto que há certo desordenamento em relação às ações realizadas. Ressalta-se, ainda, a necessidade da participação social, para que se realizem a fiscalização do serviço prestado e a participação direta dos serviços ofertados. A democratização dos espaços para a construção de políticas se faz primordial para o desenvolvimento de projetos societários que não sejam violentos, privativos, opressores e autoritários.

A política social surge de forma fragmentada, contraditória, mas necessária. Assim, o movimento da política pública e social ocorre por meio de uma redistribuição horizontal, a partir de políticas compensatórias e de cunho seletivo, estritamente para a população extremamente 
miserável. Nesse aspecto, a política social isolada não consegue conter a crise financeira, política e social. Diante desse cenário, as políticas públicas e sociais são importantes, quando baseadas na perspectiva de totalidade, ou seja, pela análise articulada da conjuntura, sendo, assim, ressaltadas por meio da luta de classes.

Essa realidade se reflete diretamente na problemática da violência contra as mulheres, uma vez que torna-se necessário um amplo apoio para a saída da mulher do contexto violento. A realidade evidencia um retrocesso de direitos que atinge, principalmente, a parcela mais pobre da população e grupos vulneráveis, como mulheres pobres e negras.

No contexto profissional, ao articular a realidade com a conjuntura, são verificadas alguns limitações em relação à essa atuação. A flexibilização do trabalho, a tendência à não especialização, a competitividade e a fragmentação das profissões são elementos que fortalecem os obstáculos do exercício profissional adequado. Nesse sentido, o compromisso ético e a formação continuada necessitam estar alinhados no exercício profissional.

Destarte, a ausência de especializações e articulação dos serviços de atendimento nos processos de avaliação, controle e tomada de decisão reflete um desinteresse por parte das entidades responsáveis. Com isso, faz-se urgente a necessidade de mais ações articuladas e oriundas do PNEVM e PNVM, na DEAM e CREAS, com uma perspectiva de universalidade e efetividade de direitos.

Os movimentos feministas, assim como os movimentos LGBTQI+ e outros, contribuem para a desnaturalização da ideologia patriarcal. A atuação de coletivos de mulheres e feministas, de maneira organizada, produz transformações necessárias que colocam em debate a questão da violência em suas várias nuances. Para tanto, é importante a resistência, a resiliência, a luta e o enfrentamento do fenômeno da violência contra as mulheres, em uma perspectiva crítica de totalidade. Contudo, o cenário político brasileiro tem fundamentado e reforçado os estereótipos de gênero e as diversas formas de opressão contra as mulheres. $O$ Estado é também responsável quando não oferece subsídios para a proteção dessas mulheres, seja no espaço público ou privado. A segurança pública, ainda que importante, não deve ser limitada ao viés punitivista e policial. Assim, faz-se necessário, ainda, modificar normas culturais e sociais, relacionando as perspectivas de raça, classe e geração nas agendas de gênero.

\section{REFERÊNCIAS}


ANDRADE, Luciana Vieira Rubim; CAMPOS, Mariana de Lima. A institucionalização de políticas de enfrentamento às violências contra as mulheres em minas gerais: conquistas, entraves e desafios. Feminismos, v. 6, n 1, p. 78-89, 2018.

ARAÚJO, Annamaria da Silva. Política Social Pública de Enfrentamento à Violência Contra a Mulher: uma tentativa de garantia dos direitos humanos das mulheres. In: V Jornada Internacional de Políticas Públicas. Anais [...]. São Luís, Brasil,2011.

ARRUZZA, Cinzia. Considerações sobre gênero: reabrindo o debate sobre patriarcado e/ou capitalismo. Revista Outubro, n. 23, p. 33-58, 2015. Disponível em: http://outubrorevista.com.br/wpcontent/uploads/2015/06/2015_1_04_Cinzia-Arruza.pdf

BANDEIRA, Lourdes Maria. Três décadas de resistência feminista contra o sexismo e a Violência feminina no Brasil: 1976 a 2006. Sociedade e Estado, v. 24, n. 2, p. 401-438, 2009.

BANDEIRA, Lourdes Maria; DE ALMEIDA, Tânia Mara Campos. A transversalidade de gênero nas políticas públicas. Revista do CEAM, v. 2, n. 1, p. 35, 2013.

BARDIN, Laurence. Análise de Conteúdo. Tradução: Luís Augusto Pinheiro. São Paulo: Edições 70, 2016.

BRASIL. Presidência da República. Lei no. 11.340, de 07 de agosto de 2006. Disponível em: http://www.planalto.gov.br/ccivil_03/_ato2004-2006/2006/lei/l11340.htm. Acesso em: 20/05/2020

BRASIL. Secretaria de Políticas Públicas para as Mulheres. Rede de enfrentamento à violência contra as mulheres. Brasília: SPM, 2011. Disponível em: http://www.spm.gov.br/sobre/publicacoes/publicacoes/2011/rede-de-enfrentamento. Acesso em: $10 / 11 / 2019$

BRASIL. SIPS: Sistema de indicadores de percepção social. Tolerância social à violência contra as mulheres. Brasília: IPEA, 2014. Disponível em: http://ipea.gov.br/portal/images/stories/PDFs/SIPS/140327_sips_violencia_mulheres.pdf.

Acesso em: 16/06/2019

CAMPOS, Mariana de Lima. BRASIL, Flávia de Paula Duque. Mulheres do campo e políticas voltadas para o enfrentamento da violência: Um estudo com foco nas ações desenvolvidas em Minas Gerais. In: Seminário Internacional Fazendo Gênero, Anais [...]. Florianópolis, 2017.

COSTA, Ana Alice Alcantara; SARDENBERG, Cecilia Maria Bacellar. (Org.). Introdução. In: $\mathbf{O}$ feminismo no Brasil: reflexões teóricas e perspectivas. Salvador: UFBA/NEIM, 2008. pp. 2331. Disponível em: http://www.neim.ufba.br/wp/wpcontent/uploads/2013/11/feminismovinteanos.pdf. Acesso em: 10/05/2019

CORRÊA, Mariza. Repensando a Família Patriarcal Brasileira (notas para o estudo das formas de organização familiar no Brasil). In: Almeida, Maria S. Kofes de et al. Colcha de Retalhos. São Paulo-SP: Brasiliense, 1982. p.13-38.

GREGORI, Maria Filomena. Cenas e Queixas: um estudo sobre mulheres, relações violentas e práticas femininas. Rio de Janeiro: Paz e Terra, 1993. 
MATOS, Marlise. Quarta onda feminista e o Campo crítico-emancipatório das diferenças no Brasil: entre a destradicionalização social e o neoconservadorismo político. Encontro Anual da ANPOCS, 2014. Anais [...]. Caxambu, 2014.

MARTINS, Ana Paula Antunes; CERQUEIRA, Daniel; MATOS, Maria Vieira Martins. A institucionalização das políticas públicas de enfrentamento à violência contra as mulheres no Brasil (versão preliminar). Nota Técnica n. 13. Brasília: IPEA, 2015.

PASINATO, Wânia; SANTOS Cecilia MacDowell. Mapeamento das Delegacias da Mulher no Brasil. Campinas: PAGU/UNICAMP; $2008 . \quad$ Disponível em: http//www.observatorioseguranca.org/pdf/MAPEO_Brasil[1].pdf. Acesso em: 20/05/2019

PASINATO, Wânia. Oito anos de Lei Maria da Penha. Entre avanços, obstáculos e desafios. Estudos Feministas, v. 23, n. 2, 2015.

PASINATO Wânia. Atendimento às mulheres em situação de violência em Belo Horizonte. In: LEOCÁDIO, Elcylene; LIBARDONI, Marlene (org.). O desafio de construir redes de atenção às mulheres em situação de violência. Brasilia: Agende, 2006.

REZENDE, Daniela Leandra; ANDRADE, Luciana Vieira Rubim. Rede não especializada de atendimento à mulher em situação de violência em Viçosa, Minas Gerais. Revista de C. Humanas. Viçosa, v 14, n. 1, p. 207-225, 2014.

RIBEIRO, Daniella Borges. ROSA, Edinete Maria. Os serviços de atendimento à mulher em situação de violência no município de Serra/ES. Revista Textos \& Contextos. Porto Alegre, v. 9, n. 1, 2010.

SANTOS, Cecília MacDowell. Da delegacia da mulher à Lei Maria da Penha: absorção/tradução de demandas feministas pelo Estado. Revista crítica de ciências sociais, n. 89, p. 153-170, 2010. Disponível em: https://journals.openedition.org/rccs/3759. Acesso em: $20 / 05 / 2019$

SCOTT, Joan. Uma categoria útil para análise histórica. Cadernos de Historia UFPE, n. 11, 2016. Disponível em: www.revista.ufpe.br/cadernosdehistoriaufpe/index.php/

cadernosdehistoriaufpe/article/download/27/19

SILVA, Rosa Maria Frugoli A Delegacia dos Fundos: uma etnografia na Delegacia Especializada de Atendimento à Mulher. São Paulo. Tese (Doutorado) - Universidade Federal de São Paulo (UNIFESP), 2017.

SILVEIRA, Lenira Politano da. Serviços de atendimento a mulheres vítimas de violência. In: DINIZ, Simone G. et al. (Org.) Vinte e cinco anos de respostas brasileiras em violência contra a mulher (1980-2005): alcances e limites. São Paulo: Coletivo Feminista Sexualidade e Saúde, 2006. p. 45-77

SOUZA, Viviana Monteiro Costa; CORDEIRO, Rosineide de Lourdes Meira. Os desafios das redes de enfrentamento à violência doméstica no Recife. Ciências humanas e sociais, v. 1, n. 3, p. 91-109. Recife, 2014. 